\title{
PERCEPÇÃO DE MÃES E PAIS ADOLESCENTES SOBRE O ALEITAMENTO MATERNO
}

Willidiane Tessari ${ }^{1}$, Larissa Gramazio Soares ${ }^{1}$, Leticia Gramazio Soares ${ }^{1}$, Isabella Schroeder Abreu

Objetivo: compreender a percepção de mães e pais adolescentes sobre o aleitamento materno. Metodologia: estudo descritivo, qualitativo, cujos participantes foram 11 adolescentes, os quais foram selecionados em uma maternidade do Paraná, para posterior coleta de dados no domicílio, 30 dias após a alta hospitalar. Os dados foram coletados no ano de 2017, por meio de entrevistas individuais amparadas por roteiro semiestruturado. Posteriormente as entrevistas foram transcritas e analisadas pela técnica de análise de conteúdo. Resultados: emergiram cinco categorias: preparo e apoio da mãe adolescente; função paternal no processo de amamentação; conhecimento sobre aleitamento materno; dificuldade de amamentar na adolescência e vivenciando a amamentação na adolescência. Conclusão: os adolescentes reconhecem a importância do aleitamento materno, recebem apoio familiar, mas os serviços de saúde apresentam lacunas assistenciais a serem superadas.

Descritores: Aleitamento Materno; Enfermagem; Adolescente.

\section{PERCEPTION OF MOTHERS AND ADOLESCENT COUNTRIES ON MATERNAL BREASTFEEDING}

Objective: to understand the perception of mothers and adolescent parents about breastfeeding. Methodology: a descriptive and qualitative study. The participants were 11 adolescents, who were selected in a maternity hospital in the state of Paraná, for later data collection at home, 30 days after hospital discharge. The data were collected in the year 2017, through individual interviews supported by semi-structured script. Subsequently the interviews were transcribed and analyzed by the content analysis technique. Results: five categories emerged: adolescent mother preparation and support; paternal role in the breastfeeding process; knowledge about breastfeeding; difficulty in breastfeeding in adolescence and experiencing breastfeeding in adolescence. Conclusion: adolescents recognize the importance of breastfeeding, receive family support, but health services present gaps to be overcome.

Descriptors: Breastfeeding; Nursing; Teenager.

\section{PERCEPCIÓN DE MADRES Y PADRES ADOLESCENTES SOBRE ELALCANCE MATERNO}

Objetivo: comprender la percepción de madres y padres adolescentes sobre la lactancia materna. Metodología: estudio descriptivo, cualitativo, cuyos participantes fueron 11 adolescentes, los cuales fueron seleccionados en una maternidad del estado de Paraná, para posterior recolección de datos en el domicilio, 30 días después del alta hospitalaria. Los datos fueron recolectados en el año 2017, por medio de entrevistas individuales amparadas por itinerario semiestructurado. Posteriormente las entrevistas fueron transcritas y analizadas por la técnica de análisis de contenido. Resultados: surgieron cinco categorías: preparación y apoyo de la madre adolescente; función paternal en el proceso de lactancia; conocimiento sobre la lactancia materna; dificultad para amamantar en la adolescencia y experimentar la lactancia materna en la adolescencia. Conclusión: los adolescentes reconocen la importancia de la lactancia materna, reciben apoyo familiar, pero los servicios de salud presentan vacios asistenciales a ser superados.

Descriptores: Lactancia Materna; Enfermería; Adolescente. 


\section{INTRODUÇÃO}

A crescente publicação de estudos sobre epigenética, células-tronco, desenvolvimento de saúde e doença nos últimos anos reúne resultados epidemiológicos relevantes, que permitem identificar alguns fatores, por exemplo, a amamentação, pode interferir na vida adulta dos indivíduos. Nesse aspecto, tais estudos fornecem subsídios para compreender a complexa importância da amamentação(1).

O aleitamento materno exclusivo deve ocorrer até os seis meses de idade do bebê e, após, ser continuada e complementada até que ele complete dois anos. O leite materno é o alimento mais completo, pois contém vitaminas, sais minerais e nutrientes necessários ao crescimento e desenvolvimento da criança, além disso, beneficia também a mãe, pois favorece a construção de vínculo afetivo, evita complicações hemorrágicas, entre outros benefícios ${ }^{(2,3)}$.

Porém, o sucesso da amamentação não é de responsabilidade apenas da mulher, mas de toda a sociedade, que pode e deve promovê-la $a^{(4)}$. Estudos assinalam fatores que podem interferir no aleitamento materno, um deles, a gravidez na adolescência. Trata-se de uma situação considerada um problema social, permeada por mudanças e dificuldades, - que acaba exigindo decisões dos futuros pais diante da sociedade ${ }^{(5)}$.

Quando ocorre a gravidez na adolescência, muitas mães não estão preparadas para essa experiência de vida e, com frequência, desconhecem a importância da amamentação e optam por seguir conselhos e práticas que enfraquecem tanto a confiança materna como a autoeficácia da prática ${ }^{(1,4-7)}$.

Nesse sentido, são necessárias estratégias que visem à promoção do aleitamento materno pela rede de atenção à saúde e rede de apoio social da nutriz ${ }^{(4)}$, assim como da figura paterna na garantia da saúde integral do binômio mãe/filho(8), pois, quando mãe e o pai são adolescentes, o risco para a não amamentação é maior ${ }^{(9)}$.

O fato das adolescentes não possuírem conhecimento das vantagens da amamentação, implica no desmame e a mulher perde a oportunidade de usufruir dos benefícios para sua própria saúde e ainda pode gerar uma culpabilização por não concretizar o papel de nutriz esperado pela sociedade ${ }^{(10)}$.

Tendo em vista as dificuldades enfrentadas, muitos mitos e tabus a cerca da amamentação, o cuidado a adolescente grávida deve ser pautado sob a ótica da integralidade, destaca-se nesse contexto o papel do enfermeiro com vistas ao acolhimento com escuta qualificada e responsabilização diante das especificidades das demandas, enfatizando as vantagens e benefícios da amamentação(11).

Atualmente, apesar da relevância do tema, nota-se que muitas pesquisas investigam a perspectiva de mulheres adultas sobre a amamentação, mas estudos realizados com adolescentes, e incluindo os pais, ainda são escassos. Portanto, espera-se que a realização desta pesquisa, forneça subsídios para a melhoria da qualidade da assistência à saúde prestada aos adolescentes, que os resultados encontrados sirvam como base para o fortalecimento do conhecimento na área de enfermagem. Assim, o objetivo do estudo foi compreender a percepção de mães e pais adolescentes sobre o aleitamento materno.

\section{METODOLOGIA}

Tipo de estudo

Trata-se de uma pesquisa descritiva de abordagem qualitativa. A Pesquisa qualitativa não requer o uso de métodos e técnicas estatísticas. $\mathrm{O}$ caráter descritivo visa descrever as características de determinada população. $\mathrm{Na}$ pesquisa descritiva, os fatos são observados, registrados, analisados, classificados e interpretados. Para coletar tais dados, utiliza-se de técnicas específicas, dentre as quais se destacam a entrevista, o formulário, o questionário, o teste e a observação(11).

\section{Participantes da pesquisa}

Participaram da pesquisa 11 respondentes, sendo um pai e dez mães adolescentes. Os critérios de inclusão foram ser pai ou mãe adolescente; na faixa etária entrel2 a 18 anos(13); aceitassem participar do estudo; e possuíssem autorização dos pais para participação, caso fossem menores de idade (12 a 17 anos). Os que apresentaram 18 anos completos não precisariam de tal autorização. Foram excluídos do estudo residentes da zona rural ou que possuíssem alguma comorbidade limitante. Houve, quatro desistências em participar do estudo, sem exposição dos motivos.

\section{Local do estudo}

A pesquisa foi desenvolvida no município de Guarapuava, situado no centro-oeste do estado do Paraná, localizado a 219 km de Curitiba e sede da 5a Regional de Saúde. A população da cidade, em 2017 foi estimada em 180.364 habitantes, em que 71.339 estavam em idade fértil ( 10 a 49 anos) $)^{(14)}$.

A assistência materna e infantil no município é organizada por meio do Programa Mamãe Guará, o qual tem por objetivo o monitoramento de todas as gestantes, puérperas e crianças nascidas vivas no municipio, que conta com 32 unidades básicas de saúde (UBS) e um ambulatório especializado, do nivel secundário. Faz parte ainda, um laboratório municipal e três particulares, credenciados ao SUS, para análises clínicas, assim como três clínicas que realizam exames de imagem. Além disso, a rede inclui dois hospitais de médio porte, ambos com maternidade de alto risco e serviços de terapia intensiva, tanto adulta como neonatal. Desde 2013, o município conta 
com um Banco de Leite Humano, que realiza o manejo do leite doado, divulgações, orientações e sensibilização de mães para que sejam doadoras e incentivam o aleitamento materno(15).

\section{Coleta de dados}

A coleta dos dados ocorreu no período de maio a julho de 2017. Primeiramente, os participantes foram selecionados em uma maternidade do município, e aproximadamente 30 dias após a alta hospitalar foram contatados por telefone para agendamento da entrevista, que foi realizada no domicílio dos participantes.

A coleta de dados foi direcionada por um instrumento semiestruturado elaborado pelas pesquisadoras com a seguinte questão disparadora: "Como está sendo a experiência de amamentar para você?" Além dessa, foi utilizada uma questão de amparo a fim instigar os sujeitos da pesquisa sobre o processo de amamentação: "Quais informações você recebeu sobre aleitamento materno durante a gravidez? Para você, o que é aleitamento materno?" Para o pai adolescente, além dessas, foram realizadas outras questões como: "Qual sua participação no pré-natal? O que você considera como sendo sua função no processo de aleitamento materno?" As entrevistas foram áudio-gravadas como meio de arquivar os relatos para posteriormente transcrevê-los. Após a transcrição as gravações foram apagadas. Cada entrevista teve duração média dez minutos.

\section{Análises dos dados}

Para a análise, utilizou-se a Análise de Conteúdo Temática, que aborda núcleos de sentido evidenciados a partir dos temas discorridos, sendo seguidas três etapas: Pré-análise, que compreende a etapa de organização dos documentos; Exploração do material, nada mais é do que a conclusão da análise e codificação das informações. Com isso, formam-se as categorias; e o Tratamento dos resultados, os quais dão o verdadeiro significado, alcançando os objetivos à pesquisa(16). Os dados obtidos através da entrevista foram cruzados com os dados da literatura, para consolidação dos mesmos.

\section{Procedimentos éticos}

O estudo foi analisado e aprovado pelo Comitê de Ética em Pesquisa envolvendo Seres Humanos (COMEP) da Universidade Estadual do Centro-Oeste (UNICENTRO), sob parecer de número 2.037.065

Foram apresentados aos participantes menores de 18 anos, o Termo de Assentimento Livre e Esclarecido e o Termo de Consentimento Livre e Esclarecido (TCLE), aos seus respectivos responsáveis. Aos participantes que tinham 18 anos completos, foi apresentado o TCLE, em duas vias, sendo assegurada uma das vias aos participantes.
Vale ressaltar, que em relação ao anonimato e confidencialidade, todos os dados de identificação dos participantes foram mantidos em sigilo, sendo que o depoimento de cada mãe e pai foi identificado pela letra $M$ (mãe) ou P (pai), seguido de um número arábico (ex: Ml, Pl)

\section{Resultados}

Os resultados serão inicialmente apresentados pela sintese dos dados relativos à caracterização dos participantes e, posteriormente, por categorias de análise, a fim de melhor contextualizar a realidade subjetiva das participantes.

Todos os participantes adolescentes do estudo são pais pela primeira vez. As mães adolescentes dedicavamse aos afazeres da casa e aos cuidados com o bebê. Após a maternidade, relataram interrupção dos estudos, o que caracteriza evasão escolar, justificada pela dificuldade de conciliar a amamentação com as atividades escolares. Àépoca da realização das entrevistas, quatro delas tinham 16 anos; duas 17 anos e quatro 18 anos. Das 10 mães entrevistadas, uma não estava amamentando decorridos aproximadamente 30 dias da alta hospitalar, porque encontrou dificuldades na pega do bebê, e outra oferecia complemento ao aleitamento. Seis mães tiveram parto normal e quatro cesárea.

Do grupo de mães entrevistadas, a maioria tinha companheiro fixo, sendo este um fator importante para o sucesso da amamentação. No que diz respeito aos pais adolescentes, apenas um participou deste estudo, pois os demais tinham mais de 18 anos e, portanto, não atendiam aos critérios de inclusão.

Em relação ao material empírico obtido por meio das entrevistas, a análise e interpretação dos dados levantados originaram cinco categorias, as quais serão apresentadas e discutidas a seguir.

\section{Preparo e apoio da mãe adolescente}

Esta categoria permitiu o entendimento que as mães adolescentes necessitam de técnicas de preparo e apoio para a amamentação, pelos serviços de saúde. Nas falas a seguir, evidencia ausência de homogeneidade no cuidado maternoinfantil, pois algumas receberam orientações apenas na maternidade e outras foram incentivadas desde o pré-natal:

"Só lá no hospital que fui orientada. No postinho, ninguém me informou" Lá, eles ensinaram que ela tem que pegar tudo essa parte escura [aréola]" (Ml).

“Durante a gravidez não me falaram nada sobre o leite materno, só depois mesmo, lá no hospital. No posto, nunca fui informada...nem grupo de gestantes, nada" (M3).

"Na unidade básica tive curso falando sobre leite" (M2).

"Nas consultas de pré-natal e eles orientaram lá no posto" $(\mathrm{Pl})$. 
Além dos serviços de saúde, emergiu das falas das participantes a família, como apoiadora da amamentação:

“Já vem de família, a mãe deu de mamar pra nós só no peito. Eu já tinha consciência. Minha família falava que era mais saudável pra criança. Minha família que me ajudou" (M4).

"Minha família falou bastante, me incentivaram bastante. Incentivaram pra eu amamentar até pelo menos seis meses. Foi no incentivo, sempre me incentivavam, até mesmo quando eu estava grávida" (M6).

\section{Função paternal no processo de amamentação}

Embora neste estudo apenas um pai tenha participado. esta categoria evidencia a importância destes sujeitos no processo de amamentação, verbalizado pelo próprio pai e corroborando com o relato de outra mãe sobre a importância do pai no processo de amamentação.

"Ela [companheira] deve amamentar bem. Minha função é sempre ajudando, auxiliando ela. É importante eu estar ali (Pl).

"Foi meu marido, ele que me ajudou na primeira mamada. Quando eu desci pro quarto, ela [criança] queria mamar daí, foi ele que me ajudou" (M8).

\section{Conhecimento sobre aleitamento materno}

Esta categoria permitiu a demonstração sobre conhecimento dos adolescentes sobre a importância da amamentação, sobretudo para o crescimento e desenvolvimento saudável da criança, tal como comprovado nas falas abaixo:

“(...) é bom pra ela, esse outro leite [complemento] está ressecando, vou ter que trocar. Se ela mamasse no peito ia ser melhor, o intestino dela não é acostumando. É bom para o crescimento dela, é melhor, pra ela é importante". (Ml)

"É mais saudável pra criança. A criança cresce mais fácil, mais ligeiro, faz mais bem pra ele. Eu sempre seguro ele com a cabeça e firmo ajudando ele, segurando e cuidando para não se afogar" (M4).

"Acho que é importante para o bebê, para o desenvolvimento dele. É bom dar até os seis meses só o leite materno" (M10).

Foi possível verificar também o entendimento das mães e do pai sobre a decisão de manterem a exclusividade do leite materno, o que é proporcionada pela compreensão sobre a composição do leite e seus benefícios, conforme verificado nas falas a seguir:

"É muito importante, como se fosse uma vacina para a criança, porque tem tudo que ele precisa. A criança cresce mais forte, é dificil ficar doente" (M6).

"Acho que é bom para a criança crescer mais, ela precisa. É bom para não causar doença. Tem tudo que a criança precisa" (Pl).
“É o alimento mais completo do bebê, não precisa dar mais nada. Eu ouvi falar que o aleitamento materno é como se fosse uma vacina, que protege o bebê de vários tipos de doenças e infecção" (M9).

\section{Dificuldade de amamentar na adolescência}

Esta categoria emergiu de situações que as mães adolescentes relataram sobre a dificuldade em amamentar, como expressos nas falas a seguir:

“No começo tinha dor, estava partindo, mas agora não. A dor quando ela puxa, daí eu não tinha bico, agora que está começando a fazer. Antes me orientaram a tomar sol, colocar pano quente se empedrar, para soltar bem o leite (M2).

"Só quando meu peito estava machucado, quando estava rachado sabe, aí estava bem dolorido(...) ensinaram minha mãe a colocar saquinho de chá e piorou mais. Ensinaram colocar uma sacola com pomada, daí tinha melhorado e começou a cozinhar por causa da sacola, tirei a sacola e continuei passando só a pomada e melhorou" (M3).

"Eu não tinha bico. Eu tinha o bico invertido, tinha mais dificuldade para dar de mamar. Isso foi um motivo que levou eu a parar de amamentar" (M5).

\section{Vivenciando a amamentação na adolescência}

Apesar das dificuldades, as participantes relataram sentimentos positivos, os quais convergiram para a categoria em questão e podem ser entendidos por meio das falas abaixo:

"Quando ele está mamando, eu me sinto feliz, aumenta o amor, mais vínculo" (M7).

"Quando estou dando de mamar para ele eu sinto uma tranquilidade, é muito bom, tem vínculo, a gente fica mais feliz" (M6).

"Quando estou amamentando sinto felicidade, é bom que ela mame desse leite, porque tem tudo que ela precisa" (M10).

"A gente se sente bem, sabendo que está podendo alimentar outra pessoa, um ser que saiu de você, é uma coisa bem diferente, questão do vínculo" (M9).

\section{DISCUSSÃO}

A maternidade e paternidade na adolescência podem ser vivenciadas de diversas formas, como um conflito de sentimentos que giram em torno da ideia de amadurecimento precoce, em que se pode desenvolver uma aprendizagem com a situação conflitante ou até mesmo vista como uma oportunidade de mudança de vida e formação de uma familia ${ }^{(17)}$.Dessa forma, os profissionais de saúde devem atuar como coadjuvantes desta experiência, para que os adolescentes aprendam a lidar com as dificuldades deste momento e para que a criança seja bem cuidada.

Uma vez que enfermeiros atuam especialmente na atenção 
primária, devem garantir o acolhimento a essa clientela e desenvolver ações contínuas. Necessitam, portanto, de conhecimento técnico-científico sobre promoção, proteção, manejo clínico, apoio e práticas de aconselhamentos durante o processo da amamentação(7,17,18). Entretanto para que os profissionais de saúde possam auxiliar efetivamente os adolescentes, precisam reconhecer as crenças e tradições que envolvem o seu contexto social, de modo a identificar práticas que desfavorecem a amamentação(19).

Tendo em vista que, algumas mães conseguem amamentar sem dificuldade, outras necessitam de ajuda no início, especialmente com o primeiro filho e, particularmente, se forem jovens ${ }^{(20)}$.

Cabe ao enfermeiro, durante as consultas de prénatal, encorajar a amamentação e, posteriormente, realizar visitas domiciliares e consultas de enfermagem para acompanhamento da mãe-bebê. Deve assistir o casal, bem como atentar para as condições biológicas, psicológicas, sociais e culturais, respeitando singularidades, decisões e conhecimentos prévios. Dessa forma, a adolescente poderá estar empoderada para esta ação, contribuindo para autonomia ${ }^{(7,17,18)}$, pois com apoio e orientações os jovens podem superar os obstáculos e vivenciar satisfatoriamente a amamentação(20)

Sobre a importância do aleitamento materno, as adolescentes deste estudo demonstraram reconhecimento e valor à prática. No entanto, estudo realizado em Teresina-PI ${ }^{(9)}$ contraria este resultado, ao apontar a falta de informações como elemento capaz de levar a adolescente a acreditar em mitos e crenças, bem como gerar sentimento de insegurança quanto ao valor nutricional do leite materno, o que pode resultar em desmame precoce.

Novamente destaca-se o papel do enfermeiro para oferecer informações sobre a amamentação, já que é um profissional educador, responsável pela assistência no ciclo gravídico-puerperal(21). Os grupos mostram-se uma ferramenta útil, sendo uma maneira de efetivar o apoio, por meio de orientações e incentivo nas atividades de cuidado(22). Portanto, espera-se que profissionais de saúde possam levar conhecimento à comunidade, em uma linguagem clara, acessivel e condizente com o entendimento de cada população(7)

O reconhecimento sobre a importância do aleitamento materno, preparo das mamas e a assistência adequada perante intercorrências no processo de aleitar asseguram benefícios para a mãe e criança, previne o desmame precoce, reconhecidos pela literatura ${ }^{(3,18)}$. Tal reconhecimento, verificado neste estudo configura-se um resultado positivo, tendo em vista que o conhecimento deficiente é preocupante, sobretudo quando envolve adolescentes ${ }^{(21)}$
Vários desafios são vivenciados por adolescentes primiparas. No entanto, quando bem orientadas, conseguem contornar as dificuldades e prosseguir com a amamentação(23).

As percepções apresentadas pelas adolescentes nesta pesquisa sobre a vivência da amamentação evidenciam que as nutrizes estão em um processo de interação com seus filhos, o que condiz com os resultados de outro estudo, que possibilitou os adolescentes a perceberem que se constrói um processo interativo com seus filhos ${ }^{(24)}$

$\mathrm{O}$ ato de amamentar é descrito como algo prazeroso, fortalece o vínculo e capaz de possibilitar uma ligação efetiva forte entre o binômio, por demandar ações de cuidado, proteção, afeto, carinho e amor(25).

No entanto, o sucesso depende da vontade da mãe em amamentar, ainda que as primeiras semanas sejam de difícil adaptação, sobretudo para as adolescentes primíparas. Assim, esta fase exige maior atenção da rede de apoio familiar e de saúde local.

Neste estudo, foi possível observar apoio para a prática do aleitamento por parte de familiares. Acresce-se o fato da maioria das adolescentes entrevistadas terem um companheiro, o que pode constituir um fator de apoio à amamentação, tal como identificado em outro estudo, em que, o companheiro exerce uma influência positiva, sendo ele, o colaborador na manutenção e apoio ao aleitamento materno(7)

A mãe e a avó materna são consideradas referência importante para esse período(18). A jovem mãe necessita de uma pessoa dedicada para fornecer apoio e transmitir confiança nessa nova etapa, receber apoio de alguém familiar ajuda a sanar seus anseios e inseguranças no processo da amamentação(22). Receber auxílio da família durante os cuidados de si e do filho(a) é um fator de proteção, uma vez que influencia na manutenção do aleitamento materno. Portanto, as ações de saúde devem ser direcionadas a todos que integram o convívio social da adolescente ${ }^{(9)}$

Evidências apontam que os cônjuges desempenham um papel significativo durante a amamentação, pois estimulam, auxiliam e encorajam as mães a mantê-la pelo maior tempo possive ${ }^{(9)}$. Nesse sentido, o relato do único pai que participou do presente estudo evidencia que ele reconhece sua importância neste processo. Recomenda-se, portanto, que os profissionais explorem esse potencial, valorizem a figura paterna, bem como suas contribuições, e desenvolvam ações voltadas para o casal adolescente. A importância do pai é reconhecida por outros estudos congêneres ${ }^{(7,21)}$

\section{Limitações do estudo}

Esse estudo teve como principal limitação o reduzido número de pais participantes, devido a poucos internamentos 
na faixa etária estabelecida como critérios de inclusão na ocorrência da pesquisa, além disso, desistência de quatro participantes.

\section{Contribuição do estudo para a prática}

O estudo em tela contribui para o fortalecimento e desenvolvimento do profissional enfermeiro, bem como a melhora nos serviços de saúde e a realização de educação permanente para atender as necessidades de uma determinada população, trazendo mais conhecimento para os/as adolescentes em relação ao aleitamento materno, ressaltando assim, a importância do apoio familiar.

\section{CONSIDERAÇÕES FINAIS}

Conclui-se que as mães e o pai adolescentes percebem a importância do aleitamento materno para seus filhos, muitos têm apoio familiar, no entanto, é possivel verificar que os serviços de saúde apresentam lacunas assistenciais, seja na orientação sobre a prática, preparo das mamas, bem como no atendimento as intercorrências habituais do processo.

Entretanto, são necessárias estratégias que promovam o aleitamento materno, tanto no que se refere ao contexto familiar e social quanto na adoção de políticas públicas que fortaleçam as práticas de amamentação e considerem os riscos de que ela não seja oferecida por falta de orientações prévias, situação a que as adolescentes estão mais expostas.

Espera-se que os resultados obtidos possam orientar os profissionais de saúde e motivar um olhar diferenciado em relação às mães adolescentes. Ressalta-se a importância de serviços de saúde com políticas públicas implementadas que sejam verdadeiramente efetivas e que fortaleçam a atenção integral aos adolescentes.

Destaca-se a necessidade de novas investigações desta natureza, pois, embora diversas pesquisas investiguem a amamentação, faltam evidências de ações eficientes para fortalecer esta prática na adolescência.

\section{Contribuição dos autores}

Willidiane Tessari: concepção, análise e interpretação dos dados, redação do artigo, revisão crítica e revisão final. Larissa Gramazio Soares: interpretação dos dados, redação do artigo, revisão crítica. Letícia Gramazio Soares: interpretação dos dados, redação do artigo, revisão crítica e revisão final. Isabella Schroeder Abreu: concepção, análise e interpretação dos dados, redação do artigo e revisão final. 


\section{REFERÊNCIAS}

1. Victora CG, Bahl R, Barros AJ, França GV, Hortan S, Krasevec $\mathrm{J}$, Murch S, et al. Breastfeeding in the 2lst century: epidemiology, mechanisms, and lifelong effect. The Lancet [Internet].2016 [cited 2017 nov 16]; 387(10017):475-90. Available from: https:// doi.org/10.1016/S0140-6736(15)01024-7.

2. Federação Brasileira das Associações de Ginecologia e Obstetricia. Manual de aleitamento materno. 3ạ ed. São Paulo; 2015.

3. Ministério da Saúde (BR). Secretaria de Atenção à Saúde. Departamento de Atenção Básica. Saúde da criança: aleitamento materno e alimentação complementar. Brasília: Ministério da Saúde;2015.

4. Rollins NC, Bhandari N, Hajeebhoy N, Horton S, Lutter CK, Martines JC. Why invest, and what it will take to improve breastfeeding practices?.The Lancet [Internet]. 2016 [cited 2017 out 30];387(10017):491-504. Available from: https://doi.org/10.1016/ S0140-6736(15)01044-2

5. Beretta RMI, Freitas MA, Dupas G, Fabbro MRC, Ruggiero EMS. A construção de um projeto na maternidade adolescente: relato de experiência. Rev Esc Enferm [Internet]. 2011[cited 2017 set 06];45(2):533-36. Available from: http://www.scielo.br/pdf/ reeusp/v45n2/v45n2a32.pdf.

6. Marques ES, Cotta RMM, Araújo RMA. Representações sociais de mulheres que amamentam sobre a amamentação e o uso de chupeta. Rev Bras Enferm [Internet]. 2009 [cited 2017 set 20];62(4):562-69. Available from: http://www.scielo.br/pdf/ reben/v62n4/12.pdf.

7. Takemoto AY, Santos AL, Okubo P, Bercini LO, Marcon SS. Preparo e Apoio à Mãe Adolescente para a Prática de Amamentação. Cienc Cuid Saude [Internet]. 2011[cited 2017 jun 27];10(3):444-51. Available from: http://periodicos.uem.br/ojs/index.php/CiencCuidSaude/article/view/17362.

8. Graça LCC, Figueiredo MCB, Conceição MTCC. Contributos da intervenção de enfermagem de cuidados de saúde primários para a promoção do aleitamento materno. Rev Latino-Am Enfermagem [Internet]. 2011[cited 2017jul 12];19(2):9 Telas. Available from: http://www.scielo.br/pdf/rlae/v19n2/pt_27.pdf.

9. Maranhão TA, Gomes KRO, Nunes LB, Moura LNB. Fatores associados ao aleitamento materno exclusivo entre mães adolescente. Cad. saúde colet [Internet]. 2015[cited 2017 ago 25]:23(2):132-39. Available from: http://www.scielo.br/pdf/cadsc/ v23n2/1414-462X-cadsc-23-2-132.pdf.

10. Prado CVC, Fabbro MRC, Ferreira GI. Desmame precoce na perspectiva de puérperas: Uma abordagem dialógica. Texto Contexto Enferm [Internet]. 2016[cited 2018jun17];25(2):el580015. Available from: www.scielo.br/pdf/tce/v25n2/pt_0104-0707-tce-25-02-1580015.pdf.

11. Ibiapina LG, Nery IS, Rocha SS, Nogueira LT, Araújo AKL, Santiago AKC. Assistência de Enfermagem ás adolescentes gestantes sob a ótica de Callista Roy. Enferm Foco. [Internet]. 2016 [cited 2018 jun 25]; 7 (3/4): 46-50. Available from: http://revista. cofen.gov.br/index.php/enfermagem/article/view/915/345

12. Prodanov, CC, Freitas, EC. Metodologia do trabalho científico: métodos e técnicas da pesquisa e do trabalho acadêmico. $2^{a}$ ed. Novo Hamburgo: FEEVALI, 2013.

13. Paraná. Estatuto da criança e do adolescente anotado e interpretado por Murillo José Digiácomo e Ildeara Amorim Digiácomo. Ministério Público do Estado do Paraná .Curitiba: Centro de Apoio Operacional das Promotorias da Criança e do Adolescente; 2013
14. Ipardes. Instituto Paranaense de Desenvolvimento Ecônomico e Social. Caderno Estatístico - Municipio de Guarapuava. Curitiba: IPARDES; 2018. [ acesso em 25 jun 2018] Disponivel em: http://www.ipardes.gov.br/perfil_municipal/MontaPerfil.php?codlocal=828btOk=ok. Acesso em: 25 de junho de 2018.

15. Secretaria Municipal de Saúde, Guarapuava. Mamãe Guará: Programa Municipal de atenção materno-infantil. Guarapuava;2013.

16. Bardin L. Análise de conteúdo. Edições 70:São Paulo; 2011.

17. Wieczorkievicz AM, Souza KV. A amamentação na adolescência sob as "lentes" do discurso do sujeito coletivo. Ágora: R. Divulg Cient [Internet]. 2010[cited 2017 dez 02];17(2):31-48. Available from: http://www.periodicos.unc.br/index.php/agora/ article/view/179.

18. Cremonese L, Wilhelm LA, Prates LA, Possati AB, Scarton, J, Ressel, LB. A decisão de amamentar durante a adolescência: um estudo na perspectiva cultural. Rev Enferm UFSM [Internet]. 2016[cited 2017 out 24];6(3):317-26. Available from: https://periodicos.ufsm.br/reufsm/article/view/19248.

19. Prates LA, Schmalfuss JM, Lipinski. JM. Amamentação: A influência familiar e o papel dos profissionais de saúde. Rev Enferm UFSM [Internet]. 2014[cited 2018 jun 21];4(2):359-367. Available from: https://periodicos.ufsm.br/reufsm/article/view/10631.

20. Sehnem GD, Tamara LB, Lipinski JM, Tier CG. Vivência da amamentação por mães adolescentes: Experiências positivas, ambivalências e dificuldades. Rev Enferm UFSM [Internet]. 2016[cited 2018 jun 22];6(4):578-588.Available from: https://periodicos.ufsm.br/reufsm/article/view/23707.

21. Bizerra RL, Carnaúba JP, Chaves AFL, Rocha RS, Vasconcelos HCA, Oriá MOB. Autoeficácia em amamentar entre mães adolescentes. Rev Eletr Enf [Internet]. 2015[cited 2017 set 22];17(3). Available from: https://www.fen.ufg.br/revista/v17/n3/pdf/ v17n3a05.pdf.

22. Cremonese L, Wilhelm LA, Prates LA, Oliveira G, Barreto CN. Ressel LB. O processo da amamentação na adolescência: Vivências rememoradas por mulheres. Rev Enferm UFPE online [Internet]. 2016[cited 2018jun 23];10(9):3284-92. Available from: https://periodicos.ufpe.br/revistas/revistaenfermagem/article/ download/11408/13185.

23. Santos EH. O desafio da amamentação para puerperas adolescentes. [Especialização em Enfermagem Pediatria e Neonatalologia]. Criciúma: Instituto de Pós Graduação de Criciúma - IPG/ESUCRI; 2012[cited 2017 ago 27]. Available from: http:// www.uniedu.sed.sc.gov.br/wp-content/uploads/2014/Ol/Eloisa-Helena-dos-Santos.pdf.

24. Camarotti CM, Nakano MAS, Pereira CR, Medeiros CP, Monteiro JCS. Perfil da prática da amamentação em grupo de mães adolescentes. Acta Paul Enferm [Internet].2011[cited 2017 out 16]; 24(1): 55-60. Available from: http://www2.unifesp.br/acta/ pdf/v24/nl/v24nla8.pdf.

25. Araújo RT, Teixeira MA, Ribeiro LVB, Barretto APV, Santos JS, Mascarenhas PM. Representações sociais do aleitamento materno para mães-adolescentes-nutrizes. Rev Enferm UERJ [Internet]. 2015[cited 2018 jun 22];23(5):639-43. Available from: http://www.e-publicacoes.uerj.br/index.php/enfermagemuerj/ article/view/11513. 